\title{
Desarrollo costero y ambientes marino-costeros en Bahía Culebra, Guanacaste, Costa Rica
}

\author{
Celeste Sánchez-Noguera ${ }^{1,2}$, Carlos Jiménez ${ }^{1,3}$ \& Jorge Cortés ${ }^{1,4}$ \\ 1. Centro de Investigación en Ciencias del Mar y Limnología (CIMAR), Universidad de Costa Rica, San Pedro, 11501- \\ 2060 San José, Costa Rica; celeste08@gmail.com \\ 2. Maestría en Gestión Integrada de Áreas Costeras Tropicales (GIACT), Universidad de Costa Rica, San Pedro, 11501- \\ 2060 San José, Costa Rica \\ 3. Enalia Physis Environmental Research Centre, Acropoleos 2, 2101 Aglanzia, Nicosia, Cyprus \\ 4. Escuela de Biología, Universidad de Costa Rica, San Pedro, 11501-2060 San José, Costa Rica
}

Recibido 28-VII-2017. Corregido 30-XI-2017. Aceptado 03-I-2018.

\begin{abstract}
Coastal development and marine ecosystems in Culebra Bay, Guanacaste, Costa Rica. Culebra Bay (North Pacific, Costa Rica) is under an accelerated process of coastal development since the implementation of the large-scale tourism development Gulf of Papagayo Project. This study aims to identify changes in the health status of marine ecosystems within the bay, during a 18yr time period (1993-2011). The high sanitary and aesthetic quality of this bay has remained constant through time. However, coral reefs are degraded and dead coral accounts for more than $65 \%$ of benthic coverage, likely due to a combination of natural and anthropogenic factors. During the study period, only one of the developers consortium has proved their commitment to accomplishing the goals of sustainable development, as established in the bay's Master Plan, through the practice of social and environmental programs. Management of natural resources in Culebra Bay requires the implementation of specific actions to promote the ecosystems' recovery, with inclusion of all stakeholders. It must consider the current use of natural resources and include water waste management and environmental education programs. Rev. Biol. Trop. 66(Suppl. 1): S309-S327. Epub 2018 April 01.
\end{abstract}

Key words: coral reefs, integrated management, tourism, pollution, Gulf of Papagayo Project.

Las zonas costeras en todo el mundo son importantes puntos de visitación turística y de acuerdo con el World Economic Forum [WEF] (2017) Costa Rica es reconocido como uno de los principales destinos turísticos en la región Latinoamericana. La provincia de Guanacaste, ubicada en el Pacífico norte de Costa Rica, posee abundantes playas de inigualable belleza escénica, así como un clima favorable la mayor parte del año. Estas cualidades motivaron que la provincia se promocionara como destino turístico de alta calidad internacional a partir de 1930 (Sánchez-Noguera, 2012a), favoreciendo el desarrollo turístico de "alto nivel" caracterizado por un enfoque de sol y playa (Fürst \& Hein, 2002).
El desarrollo turístico genera procesos de cambio acelerados en la dinámica natural de las costas (Marchant, 2006) y los impactos de dichas actividades en los ambientes marinocosteros pueden ser positivos o negativos. Según los lineamientos del modelo de desarrollo que se siga el grado de vulnerabilidad ante dichos cambios suele ser muy elevado, debido a la gran diversidad biológica que albergan estos ecosistemas (Dadon 2002; Marchant, 2006). En el caso específico de Bahía Culebra, el desarrollo turístico está basado en el esquema del proyecto Polo Turístico Golfo de Papagayo (PTGP), bajo el modelo de polo turístico internacional. Según indica el Plan Maestro y sus principios orientadores (Reglamento No 4572. 
1995) el proyecto debe enmarcarse dentro del ordenamiento vigente y en los intereses nacionales y regionales, bajo un modelo de desarrollo turístico sostenible que incorpore variables ambientales, para preservar el medio ambiente y potenciarlo como el mayor destino turístico de la región centroamericana (Alonso, 2009).

Las actividades turísticas incrementan la presión de uso de estos espacios y de los recursos albergados en ellos, a la vez que influyen de manera directa sobre el modo de vida de los habitantes locales. Un estudio efectuado por la Comisión Interinstitucional de Marinas y Atracaderos Turísticos [CIMAT] (2008) para evaluar el Índice de Fragilidad Ambiental Integrado de la costa Pacífica, revela que las secciones marinas y terrestres de Bahía Culebra exhiben valores de fragilidad ambiental "alto" y "muy alto". Además, Bahía Culebra fue descrita como un sitio de alto valor ecológico por la presencia de importantes estructuras arrecifales (Jiménez, 2001a; Cortés \& Jiménez, 2003). Se justifica entonces la necesidad de efectuar un análisis para determinar las perturbaciones naturales y los impactos ambientales de origen antrópico. En este trabajo se analiza el cambio temporal en el estado de salud de los arrecifes coralinos y la contaminación costera de los ambientes marino-costeros aledaños al proyecto PTGP y su relación con el desarrollo costero, mediante la comparación de datos generados en la década de 1990 y los periodos 2000-2001 y 2010-2011.

\section{MATERIALES Y MÉTODOS}

Sitio de estudio: Bahía Culebra, localizada dentro del Golfo de Papagayo en el Pacífico norte de Costa Rica (Fig. 1), es una bahía relativamente cerrada que alberga playas, manglares y ensenadas. Registra la máxima profundidad

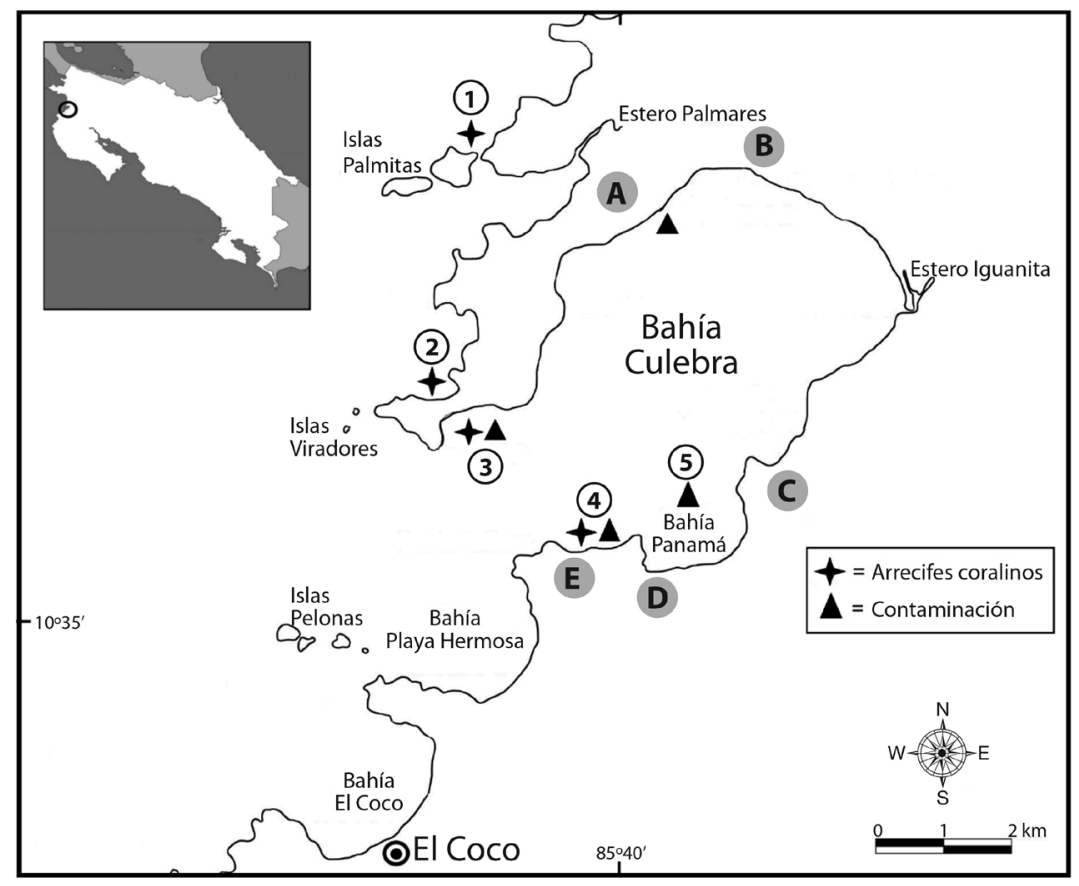

Fig. 1. Ubicación de los sitios de muestreo, Bahía Culebra, Guanacaste, Costa Rica. $1=$ Palmitas, $2=$ Güiri-Güiri, $3=$ Playa Blanca, 4 = Esmeralda, 5 = Playa Panamá. A, B, C, D y E indican la ubicación de cinco de las principales empresas concesionarias dentro del PTGP.

Fig. 1. Location of sampling sites, Bahía Culebra, Guanacaste, Costa Rica. 1 = Palmitas, 2 = Güiri-Güiri, 3 = Playa Blanca, $4=$ Esmeralda, 5 = Playa Panamá. A, B, C, D and E indicate the location of five of the main concession companies within the Gulf of Papagayo Project. 
en el sector cercano a la boca (42 m) y su área aproximada es de $24 \mathrm{~km}^{2}$ (Rodríguez-Sáenz \& Rodríguez-Fonseca, 2004). La plataforma continental en el área es relativamente estrecha, lo cual favorece la influencia de las aguas oceánicas en las zonas costeras (Jiménez, 2001a). Climatológicamente está influenciada por el desplazamiento estacional de la Zona de Convergencia Intertropical y por la acción de los vientos alisios del NE, los cuales establecen la estación seca entre diciembre y abril y la lluviosa que se extiende de mayo a noviembre (Bednarski \& Morales-Ramírez, 2004; Alfaro et al., 2012). Los ecosistemas marinos de esta bahía están influenciados por un fenómeno de surgencia o "afloramiento" costero, el cual tiene lugar durante la época seca (Brenes, León, Gutiérrez, \& Arroyo, 1990; Ballestero \& Cohen, 2004; Kessler, 2006). Dicho fenómeno se caracteriza por la surgencia de aguas profundas y frías, con un alto contenido de nutrimentos y enriquecidas en $\mathrm{CO}_{2}$ (Jiménez, 2001b; Vargas, 2002; Bednarski \& MoralesRamírez, 2004; Fiedler \& Talley, 2006; Rixen, Jiménez, \& Cortés, 2012). Se delimitó como zona de estudio el área correspondiente al PTGP, que incluye Bahía Culebra y pueblos aledaños (Fig. 1).

Contaminación costera: Se compararon los datos cuantificados entre agosto 2010 y junio 2011 con la información disponible para la misma zona en García, Acuña-González, Vargas-Zamora, \& García-Céspedes (2006). Durante los muestreos y el análisis de datos se siguió el protocolo utilizado en el proyecto de investigación "Contaminación Costera en Costa Rica (CoCosRi)" (García et al., 2006). En total se realizaron seis muestreos, uno en octubre de 2010 y cinco en 2011 (dos en marzo, dos en mayo y uno en junio). La cantidad de coliformes fecales (CF) fue el indicador microbiológico para evaluar la calidad sanitaria de aguas costeras en cuatro playas del interior de la bahía (Playa Panamá, Playa Esmeralda, Playa Blanca y Playa Sombrero) (Fig. 1). Para clasificar la calidad del agua de mar se utilizó el promedio geométrico de $\mathrm{CF} / 100 \mathrm{~mL}$ (Mora,
Rojas-Carrión, Sequeira-Barquero, Mata, \& Coto-Cervantes, 1989). En Playa Panamá también se cuantificó la contaminación por desechos sólidos y residuos de alquitrán, en un transecto de $100 \mathrm{~m}$ de longitud y $3 \mathrm{~m}$ de ancho paralelo al mar. Estos muestreos se llevaron a cabo en agosto y octubre del 2010, enero, marzo, abril y mayo del 2011. Las muestras de $\mathrm{CF}$ se analizaron en el Instituto de Investigaciones en Salud (INISA) de la Universidad de Costa Rica; las muestras para determinar contaminación por desechos sólidos y residuos de alquitrán en la playa se procesaron en el Laboratorio de Oceanografía Química del Centro de Investigación en Ciencias del Mar y Limnología (CIMAR) de la Universidad de Costa Rica.

Arrecifes coralinos: Entre agosto 2010 y julio 2011 se re-evaluaron cuatro de los nueve arrecifes descritos por Jiménez (1998) en la década de 1990: Palmitas, Güiri-Güiri (Jiménez, 1998), Playa Blanca y Esmeralda (Fig. 1). La selección de sitos se basó en: 1) ubicación geográfica, para que el sector norte y sur de la bahía estuviesen igualmente representados, y 2) el estado de desarrollo de los arrecifes, para incluir los tres de mayor extensión. Para la comparación temporal se usaron las mismas categorías de Jiménez (1998) (sustrato libre, coral vivo, coral muerto, macroalgas, algas calcáreas, esponjas y otros) más una adicional (cianobacterias), para un total de ocho categorías evaluadas.

Se realizaron 44 transectos entre $1.5 \mathrm{~m}$ y $11 \mathrm{~m}$ de profundidad. En cada arrecife se cuantificó la composición y abundancia de especies, la cobertura de coral vivo y muerto, diversidad total, abundancia de erizos e índice de heterogeneidad $\left(\mathrm{I}_{\mathrm{H}}\right)$. El $\mathrm{I}_{\mathrm{H}}$ se usa para determinar la rugosidad del sustrato y cambios en la irregularidad estructural del fondo. Se utilizó la metodología de transecto lineal descrita por Jiménez (1998) y se aplicó un factor de corrección para que los datos de ambos estudios fueran estadísticamente comparables, porque el tamaño de los eslabones de la cadena difirió entre años. Se usó el programa estadístico PAST para el análisis de datos. Para determinar 
la varianza de la cobertura entre sitios se aplicó el análisis de variancia de Kruskal-Wallis, la comparación entre pares se realizó por medio de Mann-Whitney con la corrección de Bonferroni para la discriminación entre grupos. Se calculó el índice de diversidad H' de ShannonWiener y el índice de equidad J' de Pielou para los corales escleractíneos (base e, Shannon \& Weaver, 1949). Posteriormente se aplicó una prueba t pareada para comparar el número de especies y los valores de los estadísticos correspondientes a cada sitio durante los periodos 1993-1996 y 2010-2011.

Concentraciones de nutrimentos: $\mathrm{La}$ concentración de nutrimentos en Bahía Culebra se evalúa periódicamente desde 1999, mediante el programa de monitoreo de ambientes coralinos (Proyecto "Sedimentación de arrecifes coralinos", CIMAR). Se utilizaron los datos históricos disponibles en dicha serie temporal, correspondientes al periodo 1999-2008, para analizar los cambios en la concentración anual de cinco nutrimentos (fosfatos, silicatos, nitritos, nitratos y amonio) en superficie y a $15 \mathrm{~m}$ de profundidad.

Compromiso ambiental de algunos actores: Entre agosto 2010 y enero 2012 se contactó con cinco de las principales empresas concesionarias (indicadas como A, B, C, D y E) (Fig. 1), para consultar sobre su compromiso ambiental y acciones específicas dirigidas a la protección de los recursos naturales de la bahía. También se concertaron entrevistas con los alcaldes municipales de Liberia y Carrillo (la administración política de la bahía recae en estos dos gobiernos locales) y el director de la oficina ejecutora del proyecto PTGP, para conocer su percepción respecto al impacto del PTGP y el compromiso ambiental asumido por las empresas concesionarias. Sólo se logró entrevistar a dos funcionarios de la empresa concesionaria A.

\section{RESULTADOS}

Contaminación costera: Entre octubre 2010 y junio 2011 Playa Panamá tuvo el mayor promedio geométrico $(17.4 \mathrm{CF} / 100 \mathrm{~mL})$ y se clasifica como "calidad buena" (Cuadro 1). La menor densidad de CF se midió en Playa Blanca, seguido por Esmeralda y Playa Sombrero (Cuadro 2), todos clasificados como "calidad excelente" (Cuadro 1). Al integrar todos los sitios y analizar la bahía como una unidad se determina que la calidad de sus aguas costeras durante el periodo de estudio es de clase AA ("aguas bacteriológicamente excelentes") y con el menor nivel de contaminación por CF (Cuadro 1,2). En el periodo 2000-2002, el promedio geométrico de CF para Bahía Culebra osciló entre $<2$ - 4 NMP/100 mL (Cuadro 2).

Entre 2010-2011 no se hallaron restos de alquitrán en Playa Panamá. Las mayores cantidades de desechos sólidos se recolectaron en el 2000 y el 2010, mientras que en el 2001 y el 2011 se cuantificó una disminución en los desechos con respecto al año previo (Fig. 2). Al evaluar la composición porcentual de los desechos sólidos (Fig. 2), el plástico y los materiales celulósicos (cartón, papel,

CUADRO 1

Criterios bacteriológicos para clasificar las aguas de mar en Costa Rica

TABLE 1

Bacteriological criteria for classifying sea waters in Costa Rica

\begin{tabular}{lcc}
$\begin{array}{c}\text { Promedio geométrico } \\
\text { de } \mathrm{CF} / 100 \mathrm{~mL}\end{array}$ & Calidad & Clase \\
$\leq 10$ & Excelente & AA \\
$>10-100$ & Buena & A \\
$>100-240$ & Regular & B \\
$>240-500$ & Mala & C \\
$>500-1000$ & Muy mala & D \\
$>1000$ & Pésima & E \\
\hline
\end{tabular}

*Fuente: Laboratorio Nacional de Aguas. 
CUADRO 2

Calidad microbiológica de Bahía Culebra, Guanacaste, Costa Rica, durante los periodos 2000-2002 y 2010-2011

TABLE 2

Microbiological quality in Bahía Culebra, Guanacaste, Costa Rica, during periods 2000-2001 and 2010-2011

\begin{tabular}{lccc}
\multicolumn{1}{c}{ Sitio } & Promedio aritmético de CF $/ 100 \mathrm{~mL}$ & Promedio geométrico de CF $/ 100 \mathrm{~mL}$ & Clasificación \\
2000 - Bahía Culebra & $<2$ & $<2$ & AA \\
2002 - Bahía Culebra & 5.0 & 4.0 & AA \\
2010-2011 - Playa Blanca & 1.8 & 1.8 & AA \\
Playa Sombrero & 42.3 & 5.1 & AA \\
Playa Panamá & 166.3 & 17.4 & A \\
Esmeralda & 3.7 & 2.5 & AA \\
Bahía Culebra & 53.5 & 4.5 & AA \\
\hline
\end{tabular}

* Para clasificar la calidad de las aguas se usa el promedio geométrico (Mora et al., 1989).

Los datos de 2000-2002 provienen de García et al. (2006).

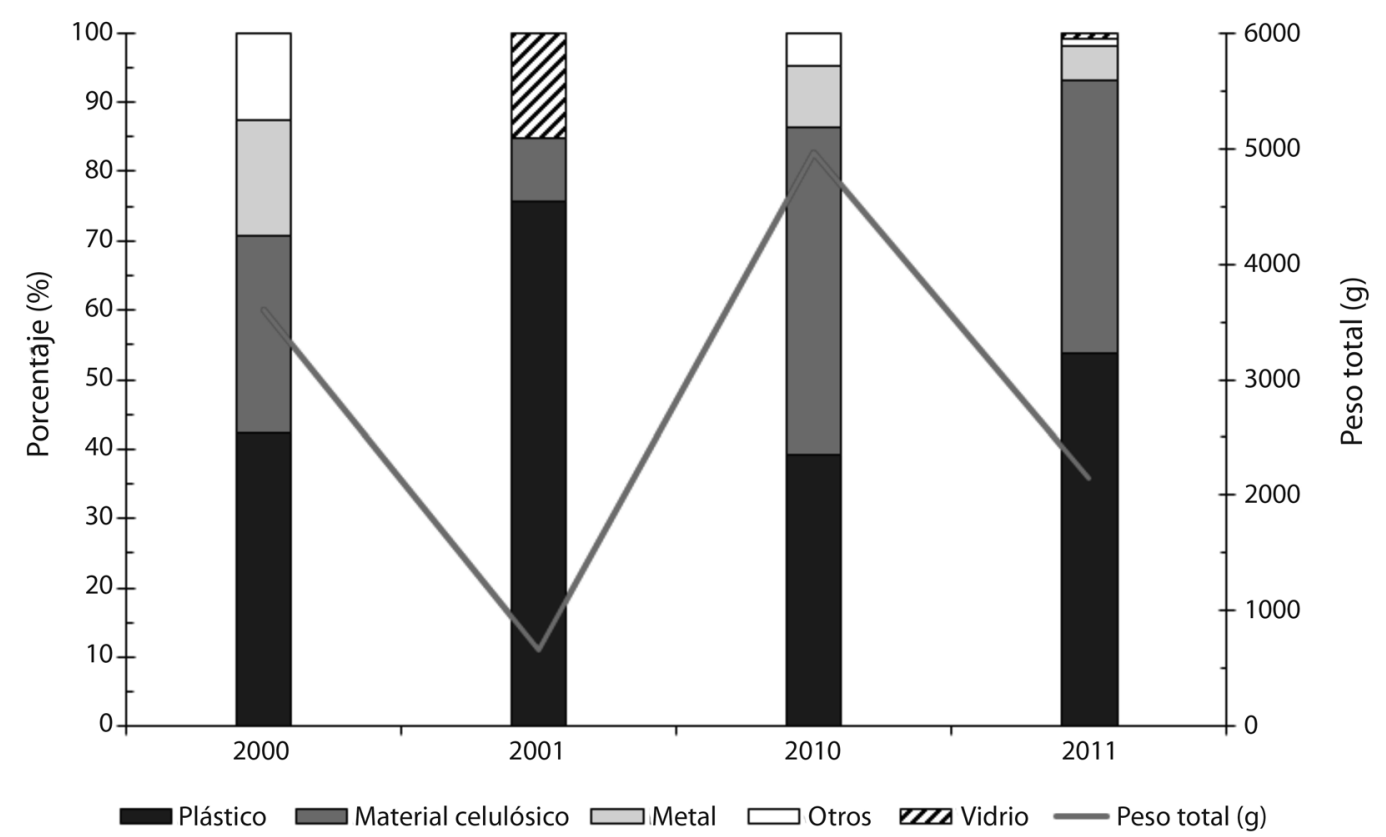

Fig. 2. Peso total (línea) y composición (barras) de los desechos sólidos depositados en Playa Panamá, Bahía Culebra, durante los periodos 2000-2001 y 2010-2011. Datos de 2000-2001 provienen de García et al. (2006).

Fig. 2. Total weight (line) and composition (bars) of solid waste collected in Playa Panamá, Bahía Culebra, during periods 2000-2001 and 2010-2011. Data from 2000-2001 were taken from García et al. (2006).

cigarrillos, fósforos, madera, restos de fogatas, restos vegetales y telas) fueron los principales contaminantes durante el periodo 2010-2011.

Arrecifes coralinos: Al analizar el cambio temporal en la composición bentóncia se observa que el coral vivo fue la categoría dominante durante 1993-1996, pero en el periodo 2010-2011 el coral muerto obtuvo los mayores porcentajes de cobertura promedio (Fig. 3). Durante este último periodo el valor más alto de coral muerto se cuantificó en Esmeralda 

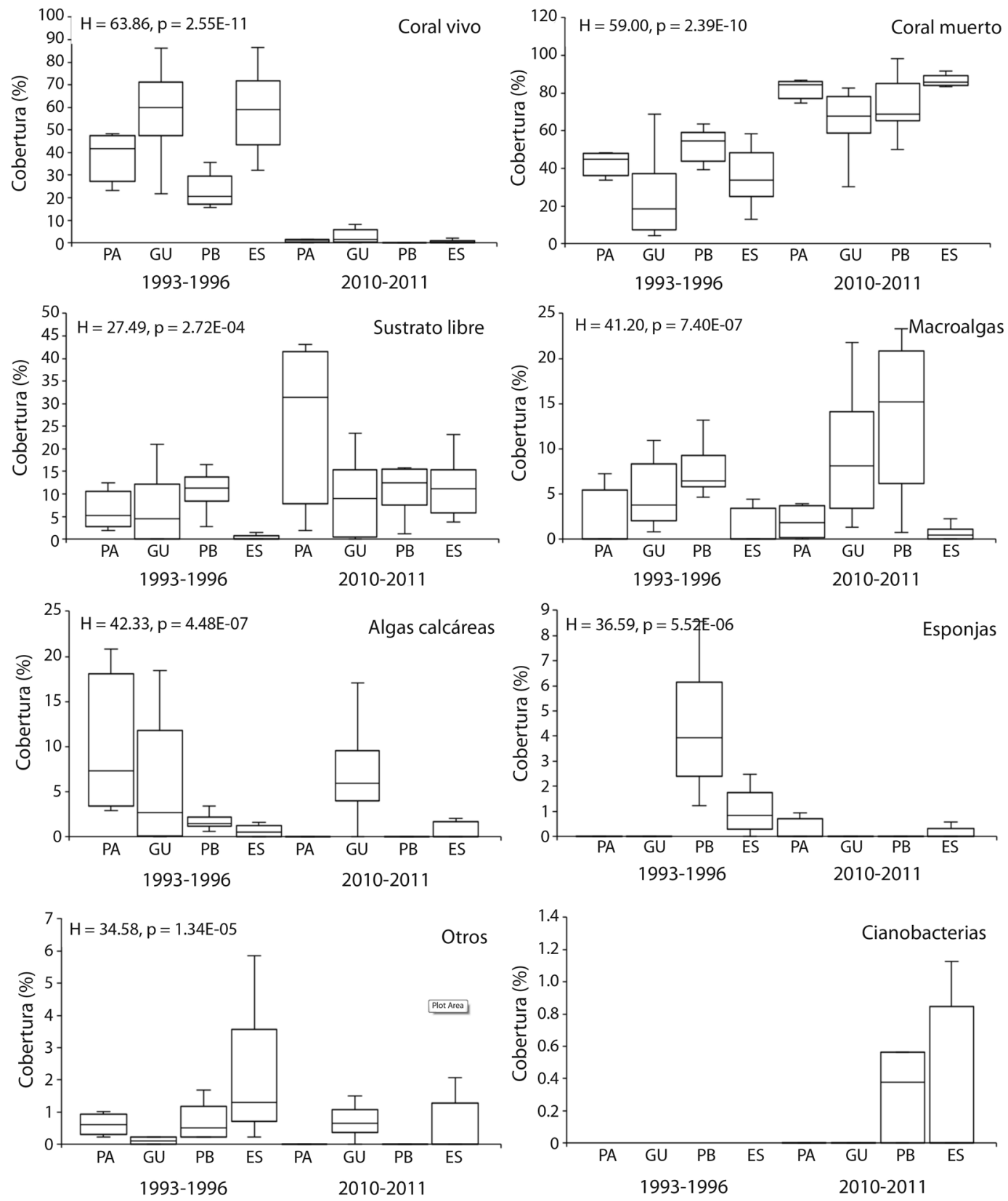

Fig. 3. Cambio temporal de la composición bentónica en cuatro sitios evaluados, Bahía Culebra, Guanacaste, Costa Rica.

Fig. 3. Temporal change of benthic composition in four sites, Bahía Culebra, Guanacaste, Costa Rica.

$(85.8 \pm 1.3 \%$, promedio \pm error estándar $)$ y el más bajo en Güiri-Güiri (67.4 $\pm 3.0 \%$ ), mientras que en 1993-1996 Playa Blanca obtuvo el valor más alto $(52.2 \pm 2.2 \%)$ y Güiri-Güiri el más bajo $(26.0 \pm 6.5 \%)$. La comparación de la composición del bentos entre periodos indica que todas las categorías evaluadas tuvieron diferencias significativas en el tiempo $(\mathrm{p}<$ 0.05) (Fig. 3), sin embargo, la comparación temporal por sitio indica que para las categorías 
de sustrato libre, macroalga, alga calcárea y esponja algunos de los sitios no presentaron diferencias significativas entre años (Cuadro 3). Las cianobacterias no tuvieron una presencia cuantificable en 1993-1996, pero durante la reevaluación se cuantificaron en tres de los cuatro sitios visitados, todos con valores similares

\section{CUADRO 3}

Valores de Kruskal-Wallis para la comparación por sitio del cambio temporal (1993-1996 y 2010-2011) en la composición del bentos, Bahía Culebra, Guanacaste, Costa Rica

TABLE 3

Kruskal-Wallis values for comparing the temporal change (1993-1996 y 2010-2011) of benthic compositon by site, Bahía Culebra, Guanacaste, Costa Rica

\begin{tabular}{|c|c|c|}
\hline Categoría & $\mathrm{H}$ & $\mathrm{p}$ \\
\hline \multicolumn{3}{|l|}{ Coral vivo } \\
\hline Palmitas & 5.33 & $0.02 *$ \\
\hline Güiri-Güiri & 18.67 & $1.55 \mathrm{E}-05^{*}$ \\
\hline Playa Blanca & 11.29 & 7.77E-04* \\
\hline Esmeralda & 17.28 & $3.23 \mathrm{E}-05^{*}$ \\
\hline \multicolumn{3}{|l|}{ Coral muerto } \\
\hline Palmitas & 5.33 & $0.02 *$ \\
\hline Güiri-Güiri & 14.55 & $1.36 \mathrm{E}-04 *$ \\
\hline Playa Blanca & 8.04 & $4.57 \mathrm{E}-03 *$ \\
\hline Esmeralda & 17.28 & $3.23 \mathrm{E}-05^{*}$ \\
\hline \multicolumn{3}{|l|}{ Sustrato libre } \\
\hline Palmitas & 1.33 & 0.25 \\
\hline Güiri-Güiri & 0.87 & 0.35 \\
\hline Playa Blanca & 0.17 & 0.67 \\
\hline Esmeralda & 16.33 & $5.3 \mathrm{E}-05^{*}$ \\
\hline \multicolumn{3}{|l|}{ Macroalga } \\
\hline Palmitas & 0.52 & 0.47 \\
\hline Güiri-Güiri & 3.94 & $0.04 *$ \\
\hline Playa Blanca & 2.16 & 0.14 \\
\hline Esmeralda & 0.56 & 0.45 \\
\hline \multicolumn{3}{|l|}{ Alga calcárea } \\
\hline Palmitas & 5.33 & $0.02 *$ \\
\hline Güiri-Güiri & 1.23 & 0.27 \\
\hline Playa Blanca & 11.29 & $7.78 \mathrm{E}-04 *$ \\
\hline Esmeralda & 0.65 & 0.42 \\
\hline \multicolumn{3}{|l|}{ Esponja } \\
\hline Palmitas & 0.33 & 0.56 \\
\hline Güiri-Güiri & 0.49 & 0.48 \\
\hline Playa Blanca & 11.29 & 7.78E-04* \\
\hline Esmeralda & 7.36 & $6.65 \mathrm{E}-03 *$ \\
\hline \multicolumn{3}{|l|}{ Otros } \\
\hline Palmitas & 5.33 & $0.02 *$ \\
\hline Güiri-Güiri & 6.5 & $0.01 *$ \\
\hline Playa Blanca & 11.29 & 7.77E-04 \\
\hline Esmeralda & 6.75 & 9.35E-03 \\
\hline
\end{tabular}

(Bonferroni; $\mathrm{p}>0.05$ ) y porcentajes promedio de cobertura inferiores al $1 \%$ (Fig. 3). Durante la re-evaluación se identificaron seis especies de corales escleractíneos (Pocillopora damicornis, Psammocora stellata, Pavona gigantea, Pavona clavus, Pavona frondifera y Porites panamensis), cuatro menos que las reportadas en 1993-1996. Güiri-Güiri fue el sitio con el mayor número de especies coralinas (cuatro). Palmitas fue el sitio con mayor diversidad ( $\mathrm{H}^{\prime}$ $\geq 1$ ) y en tres de los cuatro sitios evaluados la abundancia de especies fue bastante equitativa ( $\mathrm{J}^{\prime} \geq 0.8$ ) (Cuadro 4). La comparación temporal indica que no hubo cambios significativos en la diversidad de especies coralinas $(t=0.46 ; p=$ 0.68), sin embargo, sí se observó una reducción significativa en la riqueza $(t=3.46 ; \mathrm{p}=0.04)$ $\mathrm{y}$ un aumento significativo de la equidad $(\mathrm{t}=$ $-4.34 ; \mathrm{p}=0.02)$ de especies durante los periodos analizados (Cuadro 4).

Diadema mexicanum (Agassiz, 1863) fue el erizo más abundante en la bahía con una densidad promedio de $1.62 \pm 0.55 \mathrm{ind} / \mathrm{m}^{2}$, con variación de abundancias entre sitios. Playa Blanca tuvo la mayor densidad $4.12 \pm 0.83$ y Güiri-Güiri la menor $(0.03 \pm 0.01)(\mathrm{H}=21.32$; $\mathrm{p}<0.0001$ ) (Fig. 4). La comparación temporal

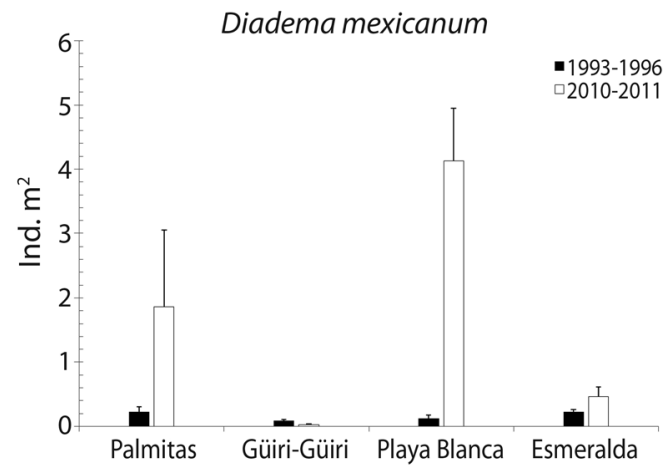

Fig. 4. Comparación temporal (barra negra $=$ década 1990, barra blanca $=2010-2011$ ) de la densidad del erizo Diadema mexicanum en los cuatro sitios evaluados, Bahía Culebra, Guanacaste, Costa Rica. Barra = promedio, línea $=$ error estándar.

Fig. 4. Temporal comparison (black bar $=$ decade 1990, white bar $=2010-2011$ ) of sea urchins (Diadema mexicanum) densities in four sites, Bahía Culebra, Guanacaste, Costa Rica. Bar $=$ average, line $=$ standar error. 
CUADRO 4

Comparación temporal de la cantidad (S), diversidad (H') y equitatibilidad (J') de especies de corales escleractíneos en los cuatro sitios evaluados, Bahía Culebra, Guanacaste, Costa Rica

TABLE 4

Temporal comparison of species richness (S), diversity (H') and evenness (J') of scleractinian corals in four sites, Bahía Culebra, Guanacaste, Costa Rica

\begin{tabular}{lcccccccc}
\multicolumn{1}{r}{$\begin{array}{c}\text { Periodo } \\
\text { Sitio }\end{array}$} & $\mathrm{N}$ & $\mathrm{S}$ & 1990's & $\mathrm{H}$ & \multicolumn{3}{c}{$2010-2011$} \\
Palmitas & 4 & 4 & 0.812 & 0.586 & 4 & 3 & 1.030 & 0.937 \\
Güiri-Güiri & 12 & 5 & 0.035 & 0.022 & 20 & 4 & 0.459 & 0.331 \\
Playa Blanca & 8 & 5 & 1.091 & 0.678 & 8 & 2 & 0.637 & 0.918 \\
Esmeralda & 12 & 5 & 1.282 & 0.797 & 12 & 2 & 0.616 & 0.888 \\
\hline
\end{tabular}

$\mathrm{N}=$ cantidad de transectos por sitio.

\section{CUADRO 5}

Comparación temporal del índice de heterogeneidad del sustrato $\left(\mathrm{I}_{\mathrm{H}}\right)$ y error estándar $(\mathrm{EE})$ en los cuatro sitios evaluados, Bahía Culebra, Guanacaste, Costa Rica

TABLE 5

Temporal comparison of rugosity index $\left(\mathrm{I}_{\mathrm{H}}\right)$ and standar error $(\mathrm{EE})$ in four sites, Bahía Culebra, Guanacaste, Costa Rica

\begin{tabular}{lccccccc}
\multicolumn{1}{c}{$\begin{array}{c}\text { Periodo } \\
\text { Sitio }\end{array}$} & $\mathrm{N}$ & $\mathrm{I}_{\mathrm{H}}$ & $\mathrm{EE}$ & $\mathrm{N}$ & $\mathrm{I}_{\mathrm{H}}$ & EE \\
Palmitas & 4 & 1.24 & 0.39 & 4 & 1.15 & 0.12 \\
Güiri-Güiri & 12 & 1.57 & 0.24 & 2011 & 1.57 & 0.19 \\
Playa Blanca & 8 & 1.16 & 0.19 & 8 & 1.17 & 0.16 \\
Esmeralda & 12 & 1.11 & 0.18 & 12 & 1.16 & 0.14 \\
\hline
\end{tabular}

$\mathrm{N}=$ cantidad de transectos por sitio.

indica un incremento en la abundancia de erizos en Bahía Culebra, el mayor cambio se presentó en Palmitas y Playa Blanca (Fig. 4).

En el periodo 2010-2011 el $\mathrm{I}_{\mathrm{H}}$ tuvo un promedio de $1.26 \pm 0.16$, con variaciones de la mediana de heterogeneidad entre sitios $(\mathrm{H}=$ 31.33; $\mathrm{p}<0.0001)$. Palmitas fue el arrecife más homogéneo $(1.15 \pm 0.12)$, desplazando a Esmeralda que durante la década de 1990 había obtenido el valor más cercano a uno (Cuadro 5). Güiri-Güiri es el único arrecife construido por colonias masivas (P. clavus) y continúa siendo el más heterogéneo $(1.57 \pm 0.19)$ de la bahía.

Concentraciones de nutrimentos: Durante el periodo 1999-2008, los silicatos y el amonio fueron los nutrimentos más abundantes en la superficie, mientras que silicatos y nitratos predominaron a $15 \mathrm{~m}$ de profundidad (Fig. 5). Con excepción de silicatos y amonio, las concentraciones en la superficie se mantuvieron relativamente estables durante la década analizada. La tendencia observada en la columna de agua indica disminución de los nitratos a lo largo del tiempo e incremento en las concentraciones de silicatos. En ambas profundidades se registró un máximo en la concentración de silicatos en 2002 y 2007, el cual estuvo acompañado durante el último año por un incremento de amonio en la superficie y de nitrato y amonio en la columna de agua (Fig. 5).

Compromiso ambiental de algunos actores: La empresa $\mathrm{A}$, concesionaria a cargo de toda la Península de Nacascolo, cuenta con una Política de Responsabilidad Ambiental cuyos 


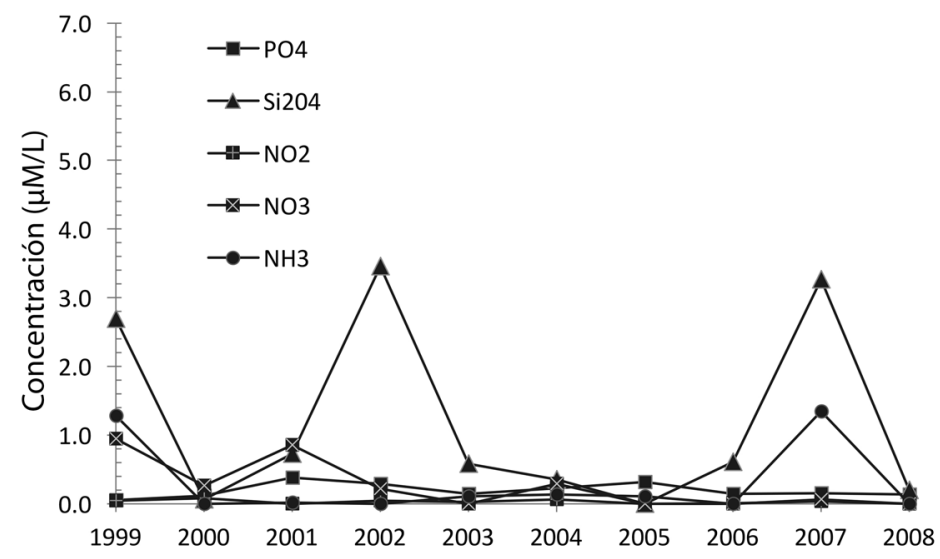

Columna de agua

(15 m)

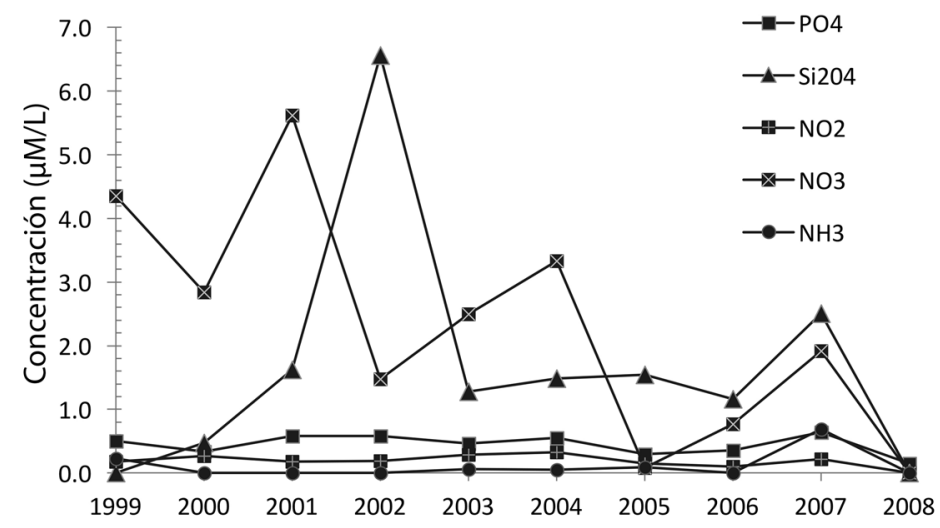

Fig. 5. Promedio anual de la concentración de cinco nutrimentos a dos profundidades, durante el periodo 1999-2008, Bahía Culebra, Guanacaste, Costa Rica.

Fig. 5. Annual average concentrations of five nutrients at two different depths during 1999-2008, Bahía Culebra, Guanacaste, Costa Rica.

ejes de trabajo incluyen: 1) campañas de concientización ambiental a lo interno y externo de la empresa (con empleados, colaboradores y comunidades locales), 2) ejecución de acciones específicas dentro de la empresa (e.g tratamiento y reutilización de aguas residuales) y con las comunidades (e.g recolección de desechos sólidos y electrónicos), y 3) apoyo continuo a programas de investigación científica ("Monitoreo de arrecifes coralinos en Bahía Culebra" y "Estudio de factibilidad del uso de agua salina en el riego del campo de golf de Península
Papagayo") (Cuadro 6). La empresa también asumió un compromiso con la protección del patrimonio arquitectónico de la zona.

\section{DISCUSIÓN}

El principal tipo de turismo en las zonas costeras se basa en la explotación de los recursos naturales, mediante usos directos como la pesca deportiva y el buceo, o indirectos como el paisajismo. Cuando este aprovechamiento no es manejado adecuadamente se produce un 


\section{CUADRO 6}

Ejes de trabajo de Península Papagayo, para cumplir con la Política de Responsabilidad Ambiental

TABLE 6

Lines of work of Península Papagayo to accomplish the Environmental Responsibility Policy

\begin{tabular}{|c|c|}
\hline Eje de trabajo & Acciones concretas \\
\hline \multirow[t]{4}{*}{ Recurso hídrico } & Planta de tratamiento manejo de aguas residuales. \\
\hline & $\begin{array}{l}\text { No se cobra por descargar aguas residuales en la Marina y se promueven que las } \\
\text { mismas no sean depositadas directamente en el océano. }\end{array}$ \\
\hline & Reutilización del $100 \%$ de las aguas residuales para riego de zonas verdes. \\
\hline & $\begin{array}{l}\text { Campo de golf se sembró con Paspallum vaginatum (especie con alta tolerancia } \\
\text { al calor y la sal). Riego con agua salina y agua residual tratada. }\end{array}$ \\
\hline \multirow[t]{2}{*}{ Manejo de desechos sólidos } & $\begin{array}{l}\text { Programa de clasificación de desechos sólidos e identificación de receptores } \\
\text { idóneos para cerrar el ciclo. }\end{array}$ \\
\hline & Recolección de desechos electrónicos en 19 comunidades. \\
\hline \multirow[t]{2}{*}{ Protección de ecosistemas marinos } & $\begin{array}{l}\text { Uso de cortinas de sedimento durante el proceso de construcción de la Marina } \\
\text { (para minimizar impacto en los arrecifes coralinos aledaños al sitio). }\end{array}$ \\
\hline & $\begin{array}{l}\text { Uso de aceites biodegradables dentro de la Marina (primera empresa en } \\
\text { utilizarlos a nivel nacional). }\end{array}$ \\
\hline \multirow[t]{2}{*}{ Protección de sitios arqueológicos } & $\begin{array}{l}\text { Modificación del diseño original de la Marina Papagayo para conservar intactas } \\
\text { dos trampas de pesca. }\end{array}$ \\
\hline & $\begin{array}{l}\text { Comunicación permanente con personal del Museo Nacional, para preservación } \\
\text { in situ otra trampa de pesca (la cual fue sepultada bajo la construcción). }\end{array}$ \\
\hline Manual de "compras verdes" & $\begin{array}{l}\text { Elección de proveedores toma en cuenta criterios de calidad, precio, buenas } \\
\text { prácticas ambientales y generación de encadenamientos productivos. }\end{array}$ \\
\hline \multirow[t]{3}{*}{ Concientización en temática ambiental } & $\begin{array}{l}\text { Programa de Educación Biológica (PEB) con centros educativos } \\
\text { de Liberia y Carrillo. }\end{array}$ \\
\hline & Campaña de Conciencia Ambiental (charlas ambientales, esfuerzos informativos). \\
\hline & Actividades para celebrar el Día del Ambiente (siembras, recolecciones, etc). \\
\hline Respeto a las áreas protegidas & Protección absoluta del humedal Palmares \\
\hline Reforestación con especies nativas & Vivero con especies forestales nativas para los programas de repoblamiento. \\
\hline \multirow[t]{2}{*}{$\begin{array}{l}\text { Apoyo a programas de } \\
\text { investigación científica }\end{array}$} & $\begin{array}{l}\text { Proyecto "Monitoreo de arrecifes coralinos en Bahía Culebra" (Universidad de } \\
\text { Costa Rica) }\end{array}$ \\
\hline & $\begin{array}{l}\text { "Estudio de factibilidad del uso de agua salina en el riego del campo de golf de } \\
\text { Península Papagayo" (Universidad de Costa Rica, Ministerio de Agricultura } \\
\text { y Ganadería) }\end{array}$ \\
\hline
\end{tabular}

Fuente: Elaboración propia con base en información de entrevistas (M. Ardón, 2012; E. Bonilla, 2011) y consulta a distintas fuentes bibliográficas (Península Pagagayo, 2005; 2010a; 2010b; 2010c).

deterioro paulatino de los sistemas marino-costeros y la alteración del equilibrio ecosistémico. Entre las principales problemáticas ambientales de las zonas costeras destacan el aumento en la demanda de agua potable para satisfacer las necesidades del desarrollo inmobiliario y turístico, la expansión acelerada de infraestructura urbano-turística, la alteración y fragmentación de los ecosistemas terrestres y marino-costeros, la salinización de los mantos acuíferos y la 
contaminación por manejo inadecuado de desechos sólidos y líquidos (Dadon, 2002; Tinoco, 2003; Contraloría General de la República, 2008; Honey, Vargas, \& Durham, 2010; Salas, 2010; TT Argos, 2010). En el marco de la gestión integrada de las zonas costeras existen diversas herramientas para analizar los modelos de desarrollo y uno de ellos es el modelo DPSIR (por sus siglas en inglés "Driving forces, Pressure, State, Impact, Response") (European Environment Agency, 1998). Este modelo ha tenido un amplio uso para evaluar servicios ecosistémicos en zonas costeras (Barragán \& Borja, 2011), dado que permite analizar las interacciones entre las presiones ambientales, el estado de los ecosistemas y la respuesta de la sociedad (United Nations Environment Programme [UNEP], 2012). En Bahía Culebra el desarrollo turístico se intensificó a partir de la década de los noventa con el surgimiento del proyecto PTGP, esto generó cambios ambientales que serán analizados mediante el modelo DPSIR (Fig. 6).

Impulsores o fuerzas motrices: Las tendencias sectoriales de cada región son los agentes impulsores de las presiones humanas, en Bahía Culebra representados por la industria turística y el desarrollo inmobiliario de alto nivel. El área terrestre del PTGP está dividida en secciones de acuerdo a las categorías de uso del suelo establecidas (Instituto Costarricense de Turismo [ICT], 2006), las cuales son otorgadas en concesión a empresas privadas y estatales para la construcción de infraestructura, como hoteles, condominios, torres de apartamentos, zonas residenciales de acceso restringido, quintas, casas vacacionales, campos de golf y pozos de agua. Adicional a estos impulsores locales, también se deben mencionar aquellos que se encuentran en una escala más global pero que tienen un impacto local, como los fenómenos del El Niño-Oscilación del Sur (ENOS) y el cambio climático (Alfaro \& Lizano, 2001; Jiménez, Cortés, León, \& Ruíz, 2001).

Presiones: Se consideran como presiones todas aquellas actividades humanas que afectan al ambiente. Dentro del Golfo de Papagayo se han identificado la pesca artesanal y la expansión de la infraestructura costera como las principales presiones (The Nature Conservancy,

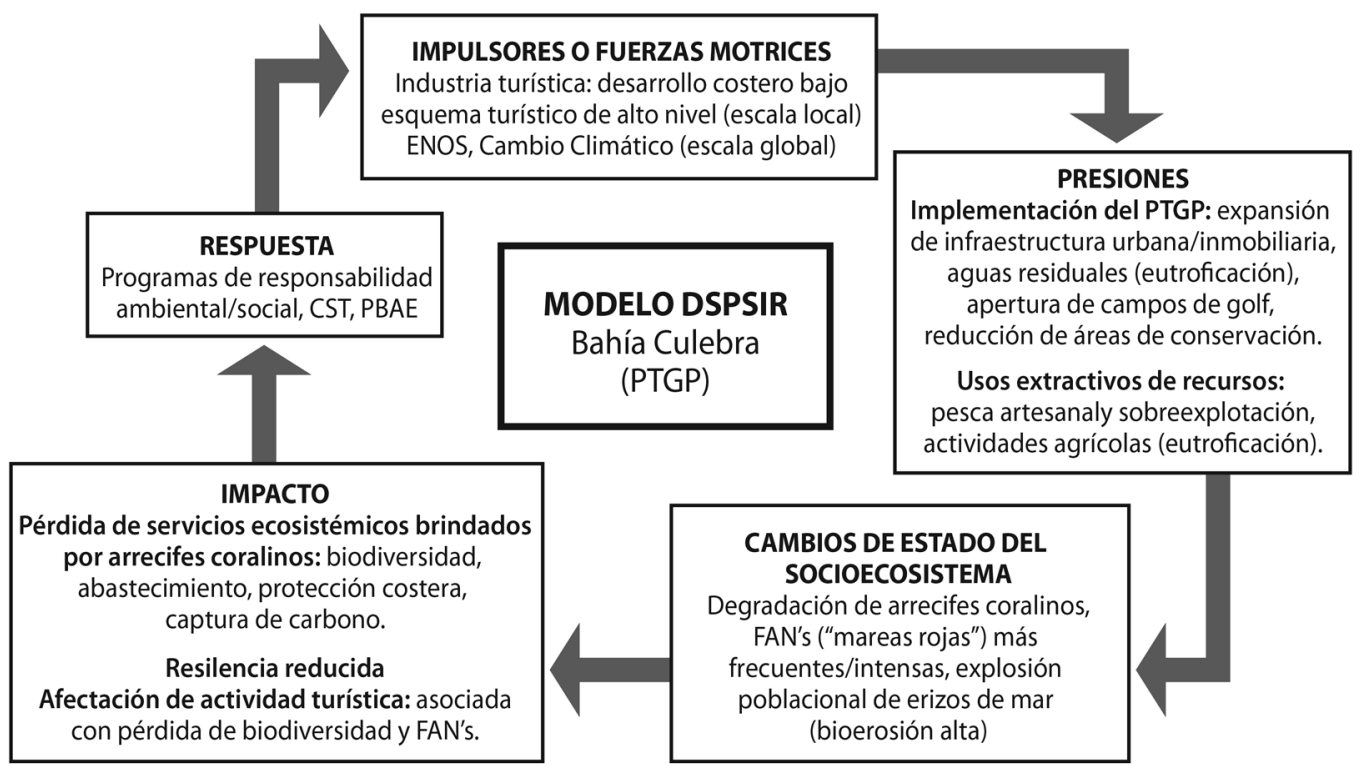

Fig. 6. Modelo de análisis DPSIR adaptado al proyecto PTGP, Bahía Culebra, Guanacaste, Costa Rica.

Fig. 6. DPSIR model adapted to Gulf of Papagayo Project, Bahía Culebra, Guanacaste, Costa Rica. 
2008), por tanto, se puede concluir que las presiones en Bahía Culebra están estrechamente relacionadas con la implementación del PTGP y los usos extractivos de los recursos (e.g. sobreexplotación pesquera, actividades agrícolas). Los cambios más relevantes en el uso del suelo dentro del PTGP entre 1978 y 2006 fueron la reducción de áreas definidas para conservación, el incremento de terrenos consignados para campos de golf y el aumento del área destinada para el desarrollo hotelero, residencial y comercial (Sánchez-Noguera, 2012a). Al 2011 existía un total de 29 concesiones vigentes dentro del PTGP (ICT, 2011), la mayoría con usos de suelo dirigidos a satisfacer las necesidades de la industria turística.

\section{Cambios de estado del socioecosistema:} Las actividades humanas ejercen presiones sobre el medio y producen cambios en los ecosistemas que son observables y cuantificables. Los cambios del socioecosistema identificados en Bahía Culebra durante este estudio se pueden agrupar en contaminación costera y arrecifes coralinos y concentraciones de nutrimentos.

Contaminación costera: Las menores concentraciones de CF se midieron frente a dos importantes hoteles, bajo la administración de diferentes concesionarias (A y E). La empresa A indicó que su proyecto cuenta con un sistema de tratamiento de aguas residuales (Península Papagayo, 2005; M. Ardón com. pers., 2012) pero se desconoce si la empresa E también posee algún sistema similar, por lo que resulta necesario estudiar las corrientes y la circulación dentro de la bahía, dado que estas podrían ser un factor determinante en los patrones de contaminación de las aguas. La mayor contaminación por CF se detectó frente a Playa Panamá, reconocida como destino predilecto para los nacionales y una de las playas más concurridas dentro del PTGP (Sánchez-Noguera, 2012a). A nivel mundial el $80 \%$ de la contaminación marina proviene de la descarga directa o indirecta de aguas residuales en la zona costera (World Health Organization [WHO], 1998), por tanto, la densidad de visitación turística y el manejo de las aguas residuales son factores altamente influyentes en la calidad sanitaria de las aguas costeras. En el periodo 2010-2011 las concentraciones de $\mathrm{CF}$ fueron mayores durante los meses de mayo y junio y dicho incremento coincide con el periodo de transición entre la época seca y la lluviosa, posiblemente debido al arrastre por escorrentía de aguas contaminadas y sedimentos terrígenos (Mora, 2007). Pese a la presencia de $\mathrm{CF}$ en varios sitios dentro de la bahía, en el periodo 1996-2005 varias playas fueron clasificadas con el nivel sanitario más alto (Clase AA) (García et al., 2006; Mora, 2007). Durante el periodo 2010-2011 también se detectó contaminación por CF en bajas concentraciones (Cuadro 2) e indica que la calidad sanitaria de las aguas costeras de Bahía Culebra oscila entre buena y excelente, condición que se ha mantenido estable en la última década.

La oscilación en la cantidad de desechos sólidos depositados en Playa Panamá durante los cuatro años de análisis (Fig. 2) evidencia que los mismos continúan siendo una externalidad negativa, exponiendo la necesidad de fortalecer los programas de consumo responsable y educación ambiental. Claramente la captura de residuos es un importante servicio ecosistémico en Bahía Culebra y por tanto un punto fundamental de análisis futuro, pues los sistemas económicos no reciclan sus desechos (Pearce \& Turner, 1995). Por tanto, si no se diseñan y ejecutan estrategias para el adecuado tratamiento de los residuos generados por la actividad turística se acelerará el proceso de degradación de los recursos naturales, que constituyen un importante capital económico en Bahía Culebra (Sánchez-Noguera, 2012b).

Arrecifes coralinos y concentraciones de nutrimentos: Los ecosistemas coralinos experimentaron un proceso de degradación entre 1993 y 2011, caracterizado por la drástica disminución en la cobertura de coral vivo (Fig. 3 ), así como la diversidad y la riqueza coralina; el cual estuvo acompañado por un reparto más equitativo de las especies remanentes. Las especies raras desaparecieron de los sitios evaluados y sólo las especies que dominaban 
la composición del bentos en la década de 1990 continúan presentes en la bahía. Si bien es cierto la cantidad de especies de coral en la bahía para el periodo 2010-2011 es menor que las presentes a mediados de los 90's, se debe tomar en cuenta que la cobertura de coral vivo también experimentó una reducción significativa en el tiempo. Estos resultados sugieren que, al estar la nueva riqueza coralina distribuida en menores porcentajes de cobertura viva, se compensa la reducción de especies en el índice y esto explica por qué los valores de diversidad no evidencian cambios significativos en el tiempo. Otro hecho relevante es la presencia reciente de cianobacterias en tres de los cuatro sitios evaluados (Esmeralda, Playa Blanca y Güiri-Güiri) (Fig. 1). La única localidad con ausencia total de cianobacterias fue Palmitas, que se encuentra más aislado de la costa y por tanto bajo menor influencia directa del desarrollo costero. No obstante, sólo mediante estudios de corrientes se podría confirmar que Palmitas no está siendo afectado por aguas contaminadas y con altos contenidos de nutrimentos, provenientes de la infraestructura turística y residencial.

El estudio reciente de los arrecifes coralinos en esta bahía se puede dividir en dos periodos, antes y después del 2007. Previo a este año los ecosistemas coralinos eran saludables y con porcentajes promedio de cobertura coralina viva que oscilaban entre 20 - 60 \% (Jiménez, 1998), pero en la década del 2000 la frecuencia e intensidad de Floraciones Algales Nocivas (FANs) en la zona aumentó drásticamente (Morales-Ramírez, Víquez, Rodríguez, \& Vargas, 2001; Vargas-Montero, Freer-Bustamante, Guzmán, \& Vargas, 2008; Jiménez et al., in prep.). Esta situación podría asociarse con los picos en las concentraciones de nutrimentos del 2002 y 2007 (Fig. 5), pero no existe evidencia suficiente para relacionar estos cambios con eventos de una escala espacial mayor porque sólo el 2007 tuvo influencia de ENOS (National Oceanic and Atmospheric Administration [NOAA], 2008). Diversos usuarios de la bahía indicaron que durante el 2007 los eventos de "mareas rojas" ocurrieron casi de manera continua (obser. pers. y comun. pers. con tour-operadores y locales). Esta prolongada exposición a las FANs produjo blanqueamiento y mortalidad coralina que dio como resultado porcentajes de coral vivo muy bajos (Fig. 3), indicando una estrecha relación entre la degradación de los arrecifes y las recurrentes FANs en la bahía. Durante los eventos de "marea roja" aumenta el consumo de oxígeno en la columna de agua y se limita la penetración de radiación solar, produciendo condiciones de estrés en los corales (Lapointe, Barile, Littler, \& Littler, 2005; Bauman, Burt, Feary, Marquis, \& Usseglio, 2010). El acelerado desarrollo marino-costero del Pacífico norte incrementa las fuentes de nutrimentos antropogénicos, por la apertura de campos de golf, nuevas actividades agrícolas y posible mal manejo de aguas residuales. El incremento espacio-temporal de las FANs en la región (Morales-Ramírez et al., 2001; Vargas-Montero et al., 2008) coincide con esta tendencia de desarrollo costero, y se convierte en un importante indicativo sobre la necesidad de implementar programas de gestión marino-costera que incluyan acciones para un manejo adecuado de las actividades productivas y las aguas residuales.

Luego de la mortalidad coralina de 2007 la estructura arrecifal comenzó a ser colonizada por diversos organismos (esponjas, vermétidos, poliquetos, anémonas) y sobrecrecida por algas calcáreas, algas filamentosas (turf) y otras macroalgas verdes y pardas. Simultáneamente la densidad de erizos incrementó significativamente, especialmente en Palmitas y Playa Blanca (Fig. 4). El incremento en las densidades del erizo D. mexicanum ocurrió a partir del 2009 y se atribuye principalmente al aumento en la disponibilidad de sustrato para forrajear (Alvarado et al., 2012), sin embargo, también se deben considerar otros factores como la reducción de depredadores producto de la sobreexplotación pesquera y el impacto del ENOS durante el periodo 2009-2010 (NOAA, 2009), dado que en otros sitios del Pacífico Tropical Oriental (PTO) también se han reportado incrementos en las poblaciones de erizos durante los eventos de ENOS (Glynn, 
1988; Guzmán \& Cortés, 1992; Alvarado et al., 2012). La presencia de D. mexicanum puede favorecer la recuperación de los arrecifes, al reducir la cobertura de macroalgas (Fig. 3) y exponer las algas calcáreas y los esqueletos que se convierten en un sustrato óptimo de asentamiento para nuevas larvas de coral (Harriott, 1983; Miller \& Ayre, 2004). Sin embargo, estos organismos también causan disturbios biológicos al remover los nuevos reclutas sexuales durante el "pastoreo" (Sammarco, 1980) y son responsables de acelerar el proceso de bioerosión de la estructura remanente (Alvarado et al., 2012). Casi todos los remanentes arrecifales dentro de la bahía se debilitaron y colapsaron producto del intenso proceso de bioerosión. Esto disminuyó su complejidad estructural, reflejada en el cambio del $\mathrm{I}_{\mathrm{H}}$. La bioerosión constituye un importante proceso destructivo en los arrecifes coralinos, porque debilita la estructura carbonatada e incrementa su susceptibilidad ante cambios ambientales (ToroFarmer, Cantera, Londoño-Cruz, Orozco, \& Neira, 2004; Alvarez-Filip et al., 2011). A pesar de que los corales en Bahía Culebra presentan las tasas de crecimiento más altas en el PTO (Jiménez \& Cortés, 2003) el reclutamiento y sobrevivencia de larvas son bajas, por lo tanto, la reducción en la heterogeneidad del sustrato posterior a los eventos de mortalidad coralina es otro indicativo del proceso de degradación del que fueron sujeto estos ecosistemas.

Impacto: Definido como los efectos que surgen a raíz de la modificación del entorno ambiental (capital natural), que en este caso comprenderían la pérdida de servicios ecosistémicos y la afectación de la actividad turística. Los arrecifes coralinos brindan una amplia variedad de servicios ecosistémicos entre los que cabe destacar la biodiversidad de especies, el abastecimiento para la sociedad, protección costera y captura de carbono (Moberg \& Folke, 1999). Cuando estos servicios ecosistémicos resultan afectados también se generan externalidades relacionadas con la actividad turística. Por ejemplo, dos de las principales actividades en las que se basa la industria turística en Bahía
Culebra son el disfrute de las playas y el buceo (Sánchez-Noguera, 2012b). Al perderse la biodiversidad de especies los turistas perderán interés en regresar a la zona. Así mismo la presencia recurrente de FAN en la zona promueve condiciones desagradables e insalubres para el disfrute de las playas, como se pudo constatar a inicios de agosto del 2017 cuando el fuerte olor de las FAN imposibilitaba la permanencia en Playas del Coco (obser. pers.).

Resiliencia de los ecosistemas: Visitas a Bahía Culebra entre agosto del 2016 y agosto del 2017 indican que el proceso de recuperación de estos ecosistemas es muy lento, con una capacidad de resiliencia limitada por diversos factores imperantes en la zona: 1) el afloramiento estacional durante la época seca modifica la química oceánica y produce condiciones ambientales estresantes para los corales (baja concentración de oxígeno, bajas temperaturas y bajo pH) (Jiménez, 1998; 2001b; Jimenez, Bassey, Segura, \& Cortés, 2010; Rixen et al., 2012), las cuales pueden resultar altamente perjudiciales luego de los eventos de mortalidad masiva; 2) el enriquecimiento de nutrimentos por causas naturales (fenómeno de surgencia) y antropogénicas (aporte de nutrimentos por el desarrollo costero) (Morales-Ramírez et al., 2001; Fernández-García, 2007; VargasMontero et al., 2008) contribuye al incremento estacional de las macroalgas invasoras (Caulerpa sertularioides) (Fernández-García, Cortés, Alvarado, \& Nivia-Ruiz, 2012) y la presencia continua de FANs (Lapointe et al., 2005); 3) las altas tasas de bioerosión reducen el sustrato disponible para la recuperación coralina; 4) la reproducción sexual en el PTO es baja y en Bahía Culebra las colonias de diferente sexo tienen un traslape mínimo durante el periodo reproductivo (Bezy, 2009). Las actividades humanas sin controles adecuados inciden directa e indirectamente en la salud de los ecosistemas marino-costeros y al combinarse con eventos de origen natural (e.g. afloramiento costero, ENOS) pueden limitar significativamente la resiliencia de estos ecosistemas. Finalmente, es importante considerar que aquellos procesos 
que ocurren en una escala espacio-temporal más amplia como el calentamiento global y la acidificación oceánica, también incidirán en su capacidad de recuperación.

Respuesta: Este apartado consiste en identificar la(s) respuesta(s) que surgen a nivel de la sociedad para solventar los problemas antes planteados. Al menos una de las empresas concesionarias dentro del PTGP ha implementado programas de responsabilidad ambiental, con acciones elaboradas y ejecutadas bajo los lineamientos de certificaciones de sostenibilidad a nivel nacional e internacional (e.g Certificado de Sostenibilidad Turística y Audubon) (Península Papagayo, 2005; Alonso, 2009; Honey et al., 2010; Península Papagayo, 2010a, b, c; Salas, 2010). Esta empresa ha dirigido esfuerzos y recursos (capital humano y económico) hacia el cumplimiento de la responsabilidad social y ambiental, acorde con los principios orientadores del Plan Maestro (Reglamento $\mathrm{N}^{\circ}$ 4572. 1995). De esta manera contribuye al desarrollo sostenible de la zona, como un proceso paralelo al modelo de desarrollo económico imperante en la provincia de Guanacaste.

El gobierno de Costa Rica también ha promovido el desarrollo sostenible del turismo costero, mediante programas nacionales como el Certificado de Sostenibilidad Turística y la Bandera Azul Ecológica. El Programa Certificado de Sostenibilidad Turística (CST) está diseñado para categorizar y certificar el grado de sostenibilidad bajo el cual operan las empresas turísticas de acuerdo al manejo de los recursos naturales, sociales y culturales. El Programa Bandera Azul Ecológica (PBAE) incentiva el desarrollo de las zonas costeras en concordancia con la protección de sus respectivas playas (Programa Bandera Azul Ecológica [PBAE], 2010). Ambas herramientas buscan que la industria turística siga ciertos criterios para la sostenibilidad social, ambiental y económica (Mora, 2007; Honey et al., 2010). Un ejemplo de ello es la disminución de desechos sólidos en Playa Panamá en el 2011 luego de la instalación de basureros en la entrada de la playa y campañas de limpieza, que demuestran el interés de algunos usuarios por mejorar la calidad sanitaria y la belleza escénica del lugar. Con esto se reitera la importancia de implementar programas locales para la gestión adecuada de los desechos sólidos, de manera que la ciudadanía cuente con las herramientas adecuadas para lograr el cambio requerido.

De las 10 unidades hoteleras que operaban durante el 2012 en el PTGP, sólo cinco poseen el CST (Programa Certificado de Sostenibilidad Turística, 2011) e igual cantidad de playas (Playa Manzanillo, Playa Monte del barco, Playa Arenilla, Playa Chorotega o Panamá y Playa Buena) han sido condecoradas con el reconocimiento PBAE (Mora, 2007; PBAE, 2010). El ICT como entidad responsable de regular el desarrollo del proyecto turístico, debe promover que todas las empresas involucradas sean certificadas con estas herramientas. Lamentablemente otras acciones del Estado no son tan beneficiosas para los recursos naturales, por ejemplo, en el 2006 se emite una declaratoria de Conveniencia Nacional para la totalidad del proyecto (Decreto Ejecutivo No. 33132-MP-T. 2006), la cual eximió a los desarrolladores dentro del PTGP de las regulaciones ambientales relacionadas con la tala de árboles (Honey et al., 2010). Esta acción incrementó el potencial de vulnerabilidad futura de los ecosistemas terrestres y marinos - los cuales resultan gravemente afectados por la sedimentación-, supeditado únicamente al grado de compromiso ambiental de las distintas concesionarias.

Al igual que la mayoría de los procesos de análisis para evaluar la gestión integral marino-costera, el modelo DPSIR se basa en la integración de información socioeconómica y ambiental. Por tanto, la cantidad y calidad de información disponible son determinantes para lograr un análisis completo e integral. Es por esto que se deben desarrollar mecanismos para fomentar la transparencia en el actuar de todas las empresas dentro del PTGP, con la finalidad de garantizar el acceso a la información sobre sus programas de responsabilidad social y ambiental. 


\section{CONCLUSIONES}

La evaluación de contaminación en Bahía Culebra permite concluir que este sitio tiene un grado alto de calidad sanitaria en sus aguas costeras, el cual ha sido constante en la escala temporal. Nuestros resultados también confirman que los arrecifes coralinos de esta bahía sufrieron una degradación drástica en los últimos años, debido a una variedad de factores de origen natural y antrópico. Esta combinación de factores dificulta la mitigación de daños, porque no todas las fuentes de impacto son fácilmente identificables o controlables. No obstante, se debe mejorar la gestión integral de los residuos y monitorear la calidad sanitaria de las aguas costeras, para la detección temprana de posibles fuentes de contaminación. El conjunto de acciones enfocado hacia una gestión integral del desarrollo de Bahía Culebra, puede contribuir a mermar la degradación y favorecer el proceso de recuperación de estos ecosistemas. Estas acciones deben involucrar al sector empresarial, institucional y comunitario, y su abordaje debe considerar cuatro ejes principales: el manejo adecuado de los residuos (especialmente los líquidos), el uso actual de los recursos, la educación ambiental y las relaciones que se desarrollan entre los distintos actores.

Es necesario fortalecer las medidas de control sobre las empresas concesionarias, para lograr cumplir con todos los principios de desarrollo sostenible estipulados en el Plan Maestro. Resulta imprescindible la adopción de un sistema actualizado que enliste los programas vigentes y las acciones de cada empresa, pues la disponibilidad de información es un pilar fundamental en la toma de decisiones. No se puede olvidar que Bahía Culebra forma parte de un desarrollo costero más amplio, que incluye toda la región del Pacífico norte de Costa Rica. Por lo tanto, la implementación de la gestión integrada en la bahía debe estar enmarcada en un plan nacional de desarrollo costero, que contemple el manejo de las actividades humanas y el uso de los recursos a lo largo del
Pacífico costarricense, con miras a mejorar los ecosistemas marino-costeros, la calidad de vida de las comunidades locales y del país en general. Dicho de otro modo, su modelo de gestión debe enfocarse en la resiliencia socioecológica, de manera que el sistema natural pueda conservar su capacidad de respuesta y adaptación ante los cambios actuales y futuros.

\section{AGRADECIMIENTOS}

El trabajo de campo se realizó gracias al apoyo del programa de monitoreo del CIMAR, mediante el proyecto de Vicerrectoría de Investigación "Sedimentación de arrecifes coralinos" (No 808-98-013). Se agradece al grupo Península Papagayo por su constante disposición a colaborar durante esta investigación, en especial a Manuel Ardón y Elsa Bonilla por las entrevistas y la documentación facilitada. Gracias a todas aquellas personas que hicieron aportes significativos para la investigación.

\section{RESUMEN}

Bahía Culebra ha experimentado un proceso acelerado de desarrollo costero desde la implementación del proyecto Polo Turístico Golfo de Papagayo. Este trabajo analiza el cambio temporal en el estado de salud sus ecosistemas marino-costeros, a partir de evaluaciones efectuadas entre 1993 y 2011. La alta calidad sanitaria y estética de la bahía se ha mantenido constante en la escala temporal. Sin embargo, los arrecifes coralinos están degradados con porcentajes de coral muerto superiores al $65 \%$ en todos los sitios, y se determina que dicho proceso es resultado de la combinación de diversos factores de origen natural y antropogénico. Sólo una empresa demostró compromiso hacia el cumplimiento de las obligaciones de sostenibilidad turísticas contempladas en el Plan Maestro, mediante la ejecución de acciones y programas de índole social y ambiental. Para gestionar adecuadamente el aprovechamiento de los recursos naturales en Bahía Culebra se deben implementar acciones que favorezcan el proceso de recuperación de los ecosistemas y que involucren a todos los actores, su abordaje debe considerar el manejo adecuado de los residuos, el uso actual de los recursos, la educación ambiental y las relaciones que se desarrollan entre los distintos actores.

Palabras clave: arrecifes coralinos, gestión integrada, turismo, contaminación, Polo Turístico Golfo de Papagayo. 


\section{REFERENCIAS}

Alfaro, E. J. \& Lizano, O. G. (2001). Algunas relaciones entre las zonas de surgencia del Pacífico Centroamericano y los océanos Pacífico y Atlántico tropicales. Revista de Biología Tropical, 49(Supl. 2), 185-193.

Alfaro, E., Cortés, J., Alvarado, J. J., Jiménez, C., León, A., Sánchez-Noguera, ... Ruiz, E. (2012). Clima y temperatura sub-superficial del mar en Bahía Culebra, Golfo de Papagayo, Costa Rica. Revista de Biología Tropical, 60(Supl. 2), 159-171.

Alonso, S. (2009). Sección III: Desarrollo local Península Papagayo. En L. Sariego, S. Alonso, M. Dierckxsens, M. Gonzalo, K. López, J. Sariego, J. Valenciano \& M. Van Lidth (Eds.). Alianzas para el desarrollo: motor de la responsabilidad Social-Casos de organizaciones públicas y privadas en Costa Rica (pp. 195-212). San José, Costa Rica: ALIARSE.

Alvarado, J. J., Cortés, J., \& Reyes-Bonilla, H. (2012). Reconstruction of Diadema mexicanum bioerosion impact on three Costa Rican Pacific coral reefs. Revista de Biología Tropical, 60(Supl. 2), 121-132.

Alvarez-Filip, L., Gill, J. A., Dulvy, N. K., Perry, A. L., Watkinson, A. R., \& Côté, I. M. (2011). Drivers of region-wide declines in architectural complexity on Caribbean reefs. Coral Reefs, 30, 1051-1060.

Ballestero, D., \& Coen, J. E. (2004). Generation and propagation of anticyclonic rings in the Gulf of Papagayo. International Journal of Remote Sensing, $25,2217-2224$

Barragán, J. M., \& Borja, F. (2011). Evaluación de los tipos operativos de ecosistemas. Litorales. En Evaluación de los Ecosistemas del Milenio de España (EME). Ecosistemas y biodiversidad de España para el bienestar humano (pp. 673-737). Madrid, España: Universidad Autónoma de Madrid y Fundación Biodiversidad.

Bauman, A. G., Burt, J. A., Feary, D. A., Marquis, E., \& Usseglio, P. (2010). Tropical harmful algal blooms: An emerging threat to coral reef communities? Marine Pollution Bulletin, 60, 2117-2122.

Bednarski, M., \& Morales-Ramírez, A. (2004). Composition, abundance and distribution of macrozoooplankton in Culebra Bay, Gulf of Papagayo, Pacific coast of Costa Rica and its values as bioindicator of pollution. Revista de Biología Tropical, 52(Supl. 2), 105-118.

Bezy, M. B. (2009). Reproducción sexual y reclutamiento del coral masivo Pavona clavus, en Bahía Culebra, Golfo de Papagayo, Costa Rica (Tesis de Maestría). San José, Costa Rica: Universidad de Costa Rica.

Brenes, C. L., León, S., Gutiérrez, A., \& Arroyo, G. (1990). Condiciones Hidrográficas En La Región de los Papagayos. Revista Geofisica, 33, 5-19.
Comisión Interinstitucional de Marinas y Atracaderos Turísticos. (2008). Índice de Fragilidad Ambiental: IFA Integrado, Mapa 75-20v. Recuperado de http://www.ict.go.cr/es/documentos-institucionales/comisi\%C3\%B3n-marinas-y-atracaderos-tur\%C3\%ADsticos-cimat/ mapas-7/guanacaste/743-7815-mapa75-20v-ifa-integrado/file.html

Contraloría General de la República. (2008). Foro Nacional: Desafíos para el Manejo Sostenible e Integral de la Zona Marítimo Terrestre. Contacto (Boletín electrónico para funcionarios de la CGR), 11, 2.

Cortés, J., \& Jiménez, C. (2003). Corals and coral reefs of the Pacific of Costa Rica: history, research and status. En J. Cortés (Ed.). Latin American Coral Reefs (pp. 361-385). Amsterdam, Netherlands: Elsevier Science B.V.

Dadon, J. R. (2002). El impacto del turismo sobre los recursos naturales costeros en la costa pampeana. En J. R. Dadon \& S. D. Matteucci (Eds.). Zona Costera de la Pampa Argentina (pp. 101-121). Buenos Aires, Argentina: Lugar Editorial.

Decreto Ejecutivo No. 33132-MP-T ("Declara de conveniencia nacional, el desarrollo y ejecución del Proyecto Turístico Golfo de Papagayo"). Diario Oficial La Gaceta 97 (2006).

European Environment Agency. (1998) Europe's Environment: The Second Assessment. Aarhus, Denmark: European Environment Agency.

Fernández-García, C. (2007). Propagación del alga Caulerpa sertularioides (Chlorophyta) en Bahía Culebra, Golfo de Papagayo, Pacífico Norte de Costa Rica (Tesis de Maestría). San José, Costa Rica: Universidad de Costa Rica.

Fernández-García, C., Cortés, J., Alvarado, J. J., \& NiviaRuiz, J. (2012). Physical factors contributing to the benthic dominance of the alga Caulerpa sertularioides (Caulerpaceae, Chlorophyta) in the upwelling Bahía Culebra, north Pacific of Costa Rica. Revista de Biología Tropical, 60(Supl. 2), 93-107.

Fiedler, P. C, \& Talley, L. D. (2006). Hydrography of the eastern tropical Pacific: a review. Progress in Oceanography, 69, 143-180.

Fürst, E., \& Hein, W. (2002). Turismo de larga distancia $y$ desarrollo regional en Costa Rica: estudios sobre las relaciones económico-ecológicas entre turismo y desarrollo sostenible en los ámbitos globales, nacionales y microregionales. San José, Costa Rica: DEI.

García, V., Acuña-González, J., Vargas-Zamora, J. A., \& García-Céspedes, J. (2006). Calidad bacteriológica y desechos sólidos en cinco ambientes costeros de Costa Rica. Revista de Biología Tropical, 54(Supl. 1), 35-48. 
Glynn, P. (1988). El Niño warming, coral mortality and reef framework destruction by echinoid bioerosion in the eastern Pacific. Galaxea, 7, 129-160.

Guzmán, H., \& Cortés, J. (1992). Cocos Island (Pacifico of Costa Rica) coral reefs after the1982-83 El Niño disturbance. Revista de Biología Tropical, 40, 309-324.

Harriott, V. (1983). Reproductive seasonality, settlement and post-settlement mortality of Pocillopora damicornis (Linnaeus), at Lizard Island, Great Barrier Reef. Coral Reefs, 2, 151-157.

Honey, M., Vargas, E., \& Durham, W. (2010). Impacto del turismo relacionado con el desarrollo en la costa Pacifica de Costa Rica (Informe ejecutivo). San José, Costa Rica: Center for Responsible Travel.

Instituto Costarricense de Turismo. (2006). Plan Maestro Polo Turístico Golfo Papagayo: Uso del suelo. San José, Costa Rica: Instituto Costarricense de Turismo (ICT).

Instituto Costarricense de Turismo. (2011). Mapa y lista de concesiones. San José, Costa Rica: Oficina Ejecutora Polo Turístico Golfo de Papagayo.

Jiménez, C. (1998). Arrecifes y comunidades coralinas de Bahía Culebra, Pacífico Norte de Costa Rica (Golfo de Papagayo) (Tesis de Maestría). San José, Costa Rica: Universidad de Costa Rica.

Jiménez, C. (2001a). Arrecifes y ambientes coralinos de Bahía Culebra, Pacífico de Costa Rica: aspectos biológicos, económico-recreativos y de manejo. Revista de Biología Tropical, 49(Supl. 2), 215-231.

Jiménez, C. (2001b). Seawater temperature measured at the surface and at two depths (7 and $12 \mathrm{~m})$ in one coral reef at Culebra Bay, Gulf of Papagayo, Costa Rica. Revista de Biología Tropical, 49(Supl. 2), 153-161.

Jiménez, C. E., \& Cortés, J. (2003) Growth of seven species of scleractinian corals in an upwelling environment of the eastern Pacific (Golfo de Papagayo, Costa Rica). Bulletin of Marine Science, 72, 187-198.

Jiménez, C., Cortés, J., León, A., \& Ruíz, E. (2001). Coral bleaching and mortality associated with the 1997-98 El Niño in an upwelling environment in the eastern Pacific (Gulf of Papagayo, Costa Rica). Bulletin of Marine Science, 69, 151-169.

Jiménez, C., Bassey, G., Segura, Á., \& Cortés, J. (2010). Characterization of the coral communities and reefs of two previously undescribed locations in the upwelling region of Gulf of Papagayo (Costa Rica). Revista Ciencias Marinas y Costeras, 2, 95-108.

Kessler, W. S. (2006). The Circulation of the Eastern Tropical Pacific: A Review. Progress in Oceanography, 69(2-4), 181-217.
Lapointe, B., Barile, P. J., Littler, M. M., \& Littler, D. (2005). Macroalgal blooms in southeast Florida coral reefs. II. Cross-shelf discrimination of nitrogen sources indicates widespread assimilation of sewage nitrogen. Harmful Algae, 4, 1106-1122.

Marchant, C. (2006). Consuelo Castro y Esteban Morales. La zona costera. Medio natural y ordenación integrada. Revista de geografia Norte Grande, 35, 97-101.

Miller, K. J., \& Ayre, D. J. (2004). The role of sexual and asexual reproduction in structuring high latitude populations of the reef coral Pocillopora damicornis. Heredity, 92, 557-568.

Moberg, F., \& Folke, C. (1999). Ecological goods and services of coral reef ecosystems. Ecological Economics, 29(2), 215-233.

Mora, D. (2007). Calidad sanitaria de las aguas de playa en Costa Rica. San José, Costa Rica: Campo Directo K.C.S.A.

Mora, D, Rojas-Carrión, J. C., Sequeira-Barquero, M. A., Mata, A., \& Coto-Cervantes, M. (1989). Criterios bacteriológicos y calidad sanitaria de las aguas de playa de Costa Rica 1986-1987. Tecnología en Marcha, ITCR, 9, 45-52.

Morales-Ramírez, A., Víquez, R., Rodríguez, K., \& Vargas, M. (2001). Marea roja producida por Lingulodinium polyedrum (Peridiniales, Dinophyceae) en Bahía Culebra, Golfo de Papagayo, Costa Rica. Revista de Biología Tropical, 49(Supl. 2), 19-23.

National Oceanic and Atmospheric Administration. (2008). National Centers for Environmental Information, State of the Climate: El Niño/Southern Oscillation for Annual 2007. National Oceanic and Atmospheric Administration (NOAA), Washinting D.C., United States of America. Recuperado de https://www.ncdc. noaa.gov/sotc/enso/200713

National Oceanic and Atmospheric Administration. (2009). El Niño Arrives; Expected to Persist through Winter 2009-10. National Oceanic and Atmospheric Administration (NOAA), Washington D.C., United States of America. Recuperado de http://www.noaanews. noaa.gov/stories2009/20090709_elnino.html

Programa Bandera Azul Ecológica. (2010). Programa Bandera Azul Ecológica. Instituto Costarricense de Acueductos y Alcantarillados (AyA), San José, Costa Rica. Recuperado de http://www.aya.go.cr/Contenidos/frwContenidos.aspx? $\mathrm{d}=17 \& \mathrm{a}=1$

Programa Certificado de Sostenibilidad Turística. (2011). Certificación para la Sostenibilidad Turística: directorio de empresas acreditadas. Certificado de Sostenibilidad Turística (CST). Instituto Costarricense de Turismo, San José, Costa Rica. Recuperado de http:// www.turismo-sostenible.co.cr 
Pearce, D., \& Turner, R. (1995). Economía de los recursos naturales y del medio ambiente. Madrid, España: Celeste Ed.

Península Papagayo. (2005). Programa de Relaciones Comunitarias "Creciendo Juntos". Memoria Quinquenal de Logros 2001-2005. San José, Costa Rica: Península Papagayo.

Península Papagayo. (2010a). Boletín Informativo $N^{\circ} 32$ “Creciendo Juntos". San José, Costa Rica: Península Papagayo.

Península Papagayo. (2010b). Boletín Informativo $N^{\circ} 34$ "Creciendo Juntos". San José, Costa Rica: Península Papagayo.

Península Papagayo. (2010c). Boletín Informativo $N^{\circ} 35$ “Creciendo Juntos". San José, Costa Rica: Península Papagayo.

Reglamento No 4572 ("Plan Maestro General del Proyecto Turístico Golfo de Papagayo"). Diario Oficial La Gaceta 140 (1995).

Rixen, T., Jiménez, C., \& Cortés, J. (2012). Impact of upwelling events on the sea water carbonate chemistry and dissolved oxygen concentration in the Gulf of Papagayo (Culebra Bay), Costa Rica: Implications for coral reefs. Revista de Biología Tropical, 60(Supl. 2), 187-195.

Rodríguez-Sáenz, K., \& Rodríguez-Fonseca, J. (2004). Avistamientos del delfín manchado, Stenella attenuata (Cetacea: Delphinidae) en Bahía Culebra, Costa Rica, 1999-2000. Revista de Biología Tropical, 49(Supl. 2), 189-193.

Salas, A. (2010). Polo Turístico Golfo de Papagayo, Guanacaste, Costa Rica: Análisis del Polo Turístico Golfo de Papagayo como un modelo único gubernamental de concesión turística. San José, Costa Rica: Center for Responsible Travel.

Sammarco, P. W. (1980). Diadema and its relationship to coral spat mortality: grazing, competition and biological disturbance. Journal of Experimental Marine Biology and Ecology, 45(2), 245-272.

Sánchez-Noguera, C. (2012a). Entre historias y culebras: más que una bahía (Bahía Culebra, Guanacaste, Costa Rica). Revista de Biología Tropical, 60(Supl. 2), 1-17.
Sánchez-Noguera, C. (2012b). Cambios socioeconómicos y ambientales en Bahía Culebra, Guanacaste, Costa Rica: Implicaciones para su gestión (Tesis de Maestría). San José, Costa Rica: Universidad de Costa Rica.

Shannon, C., \& Weaver, W. (1949). The Mathematical Theory of Communication. Illinois, EEUU: University Illinois Press.

Tinoco, O. (2003). Los impactos del turismo en el Perú. Producción y Gestión, 6, 47-60.

The Nature Conservancy. (2008). Evaluación de ecorregiones marinas en Mesoamérica. Sitios prioritarios para la conservación en las ecorregiones Bahía de Panamá, Isla del Coco y Nicoya del Pacífico Tropical Oriental, y en el Caribe de Costa Rica y Panamá. Programa de Ciencias Regional, Región de Mesoamérica y El Caribe. San José, Costa Rica: The Nature Conservacy.

Toro-Farmer, G., Cantera, J., Londoño-Cruz, E., Orozco, C., \& Neira, R. (2004). Patrones de distribución y tasas de bioerosión del erizo Centrostephanus coronatus (Diadematoida: Diadematidae), en el arrecife de Playa Blanca, Pacífico colombiano. Revista de Biología Tropical, 52, 67-76.

TT Argos. (2010). Dinámica Territorial del Desarrollo Turístico Costero: Sintesis, Conclusiones y Recomendaciones. Informe final para Center for Responsible Travel. San José, Costa Rica.

United Nations Environment Programme. (2012). Global Environment Outlook (GEO-5). Environment for the future we want. Valletta, Malta: UNEP.

Vargas, J. M. (2002). Interacción océano-atmósfera: surgencia y generación de anillos en la región de Papagayo. Revista Geográfica de América Central, 40, 133-144.

Vargas-Montero, M., Freer-Bustamante, E., Guzmán, J., \& Vargas, J. C. (2008). Florecimientos de dinoflagelados nocivos en la costa Pacífica de Costa Rica. Hidrobiológica, 18, 15-23.

World Health Organization. (1988). Guidelines for monitoring the quality of coastal recreational and shellfish growing waters. Indiana, EEUU: UNEP.

World Economic Forum. (2017). The travel \& tourism competitiveness report 2017. Geneva: World Economic Forum. 